\title{
NOMES SECRETOS E RIQUEZA VISÍVEL: NOMINAÇÃO NO NOROESTE AMAZÔNICO
}

Stephen Hugh-Jones

A relevância dos nomes pessoais e dos sistemas de nominação é uma das marcas distintivas da literatura etnográfica sobre as terras baixas da América do Sul. Se a onomástica foi regularmente excluída da pesquisa antropológica sobre o parentesco - como testemunha a literatura sobre o tema —, quando se trata das complexas estruturas sociais dos Jê e Bororo ou dos sistemas de seções kariera dos Pano, as relações baseadas na transferência de nomes mostram-se de importância crucial ${ }^{1}$. Acompanhando os trabalhos pioneiros sobre esses grupos, a maioria das monografias a respeito dos ameríndios das terras baixas inclui agora uma seção dedicada aos nomes e à nominação e algumas são inteiramente devotadas a este tópico (ver Gonçalves 1993).

Em um conhecido excurso comparativo, Viveiros de Castro sugere que os sistemas de nominação ameríndios podem ser classificados em um continuum que iria do pólo "exonímico" ao pólo "endonímico". Nos sistemas exonímicos dos Ikpeng, Yanomamö, Araweté e outros grupos tupi, os nomes vêm do exterior e dos Outros: deuses, mortos, inimigos ou animais. Nos sistemas endonímicos de povos jê, como os Kayapó e Timbira, os nomes, assim como os bens herdados, são mantidos no interior do grupo, constituindo parte de sua propriedade e identidade corporadas e designando relações sociais particulares. Além disso, para os exonímicos tupinambá, a ênfase estava na aquisição individual, heróica, de nomes singulares e não transmissíveis que individualizavam seu portador; para os endonímicos kayapó, por outro lado, a ênfase está na transmissão intervivos, coletivamente sancionada e cerimonializada, que mantém um estoque limitado de nomes em perpétua circulação. No primeiro caso, os nomes pertencem ao domínio da metafísica e possuem uma função individualizante; no último, eles remetem à ordem social e têm funções classificatórias (Viveiros de Castro 1986:151-155).

Os povos tukano do Noroeste Amazônico, que Viveiros de Castro coloca no pólo endonímico do continuum, são dos mais bem documentados das 
terras baixas da América do Sul. No entanto, apesar da importância dos nomes e da nominação na constituição e perpetuação dos grupos patrilineares tukano, grupos análogos às corporações de perfil "matrilinear" e base onomástica kayapó, timbira e bororo, as informações sobre a onomástica tukano são esparsas e dispersas ${ }^{2}$. Um dos objetivos deste trabalho consiste simplesmente em reunir alguns dados básicos sobre a onomástica tukano, que irão tanto complementar as informações sobre outros lugares na Amazônia quanto esclarecer a natureza da "patrilinearidade" [patriliny] tukano (ver, também, S. Hugh-Jones 1995). Gostaria ainda de explorar o papel dos nomes e da nominação na constituição da pessoa, observando as ocasiões ritualizadas de nascimento, iniciação e morte, quando os nomes e a nominação passam a primeiro plano. Finalmente, utilizarei os insights de Viveiros de Castro para situar esse material em um contexto comparativo. Em particular, apreciaria mostrar que, embora seu padrão seja basicamente endonímico, não é exclusivamente assim e que há algumas diferenças importantes entre o sistema de nominação dos Tukano e aquele dos Jê e dos Bororo.

\section{Os Tukano e seus nomes}

Os Tukano compreendem um sistema social aberto localizado na região Vaupés-Uaupés ao longo da fronteira equatorial entre a Colômbia e o Brasil. Estão divididos em cerca de quinze ou mais grupos interligados matrimonialmente, cada um deles associado a um território particular, que reivindica descendência de um ancestral comum e que possui um conjunto distintivo de bens que inclui instrumentos musicais sagrados, ornamentos plumários, músicas, cantos, fórmulas mágicas e nomes. Em princípio, cada grupo exogâmico possui e fala uma língua diferente, de modo que as pessoas deveriam se casar com falantes de uma língua distinta da sua, um traço associado ao multilingüismo sistêmico. Antigamente, os Tukano viviam em grandes casas multifamiliares ou malocas, sendo o núcleo residencial formado por um grupo de irmãos com suas esposas; atualmente, a maioria vive em aldeias nucleadas, inspiradas nas missões. Os dados de que disponho provêm basicamente da pesquisa de campo entre os Bará (B), Barasana, Makuna (M), Taiwano e Tatuyo (T) da bacia do Pirá-Paraná e de trabalhos publicados sobre os Makuna, Tukano (Tu) ${ }^{3}$ e Cubeo. No entanto, tudo parece sugerir que, com pequenas variações, o sistema de nomes e nominação de que vou tratar é comum a todos os grupos tukano do Noroeste Amazônico e, provavelmente, também aos seus vizinhos baniwa (ver, p. ex., Journet 1995:52-54). 
Uma extensa investigação dos etnônimos tukano está além do escopo deste trabalho. No entanto, como esclarecerei a seguir, qualquer discussão sobre os nomes pessoais tukano deve incluir, necessariamente, alguma referência aos nomes dos grupos e dos clãs exogâmicos. Etnônimos como Barasana, Tatuio, Karapana ou Tukano, que os agentes externos usam para se referir a grupos tukano particulares, provêm, em sua maioria, da Língua Geral (LG), uma língua franca tupi difundida pelos primeiros missionários e ainda falada por algumas pessoas mais velhas no Brasil. Os próprios Tukano fazem uso regular desses etnônimos, em parte porque fornecem uma alternativa conveniente aos seus nomes de grupo sagrados ou semi-sagrados, em parte porque são aqueles empregados por agentes externos com os quais eles têm que lidar cada vez mais. Alguns nomes em língua geral são os equivalentes diretos desses nomes de grupo propriamente ditos, outros aludem a eles e outros equivalem aos nomes (sagrados, comuns ou jocosos) de um dos clãs componentes do grupo e que serve, metonimicamente, para denotar o todo. Karapana (LG) ou "Mosquito" para Mütea (K) é um exemplo de equivalência direta; Tatuio ou Tatú-Tapuio (LG), "Povo do Tatu", equivalente a Pamoa (T), nome de um dos clãs de um grupo cuja autodesignação é Hüna $(\mathrm{T})$, é um exemplo de metonímia.

Os grupos exogâmicos tukano são convencionalmente descritos como "patrilineares", um termo que poderia ser tomado para sugerir que a identidade do grupo, o pertencimento a ele e a propriedade estão todos baseados em algum princípio abstrato e a priori de descendência. Na prática, as coisas funcionam de maneira oposta: é a propriedade material e imaterial e as noções de essência, propriedade e identidade que constituem os grupos e os tornam "patrilineares" - e aqui a língua, os nomes e a nominação passam a primeiro plano. Muitos dos nomes próprios, sagrados, para os grupos exogâmicos são derivados de ou conotam o nome do ancestral do grupo e/ou a sua posição cosmológica. Assim, um dos nomes próprios dos Bará (LG) é Wai Maha (B), "Povo-Peixe", os descendentes e as manifestações de Wai Pino (B), Cobra-Peixe. Outros "Povos-Peixe" são os Pirá-Tapuio (LG, "Povo-Peixe") e os Yuruti (Wayara, "Povo-Peixe"). Uma outra manifestação de Wai Pino é Ide Hino (M), "Cobra d'Água", o ancestral do Ide Masa (M) ou Povo da Água que forma um segmento dos Makuna (LG). Portanto, os Bará, Ide Masa, os Pirá-Tapuio e os Yuruti são todos Povos-Peixe/da Água; são "irmãos" e constituem parte de uma fratria não nominada. Do mesmo modo, os Barasana (LG), que são descendentes de Yeba Meni Hino, "Cobra da Terra Meni" 4 são Yeba Masa ou "Povo da Terra". Outro "Povo da Terra" são os Tukano (LG) ou Ye'pa Masa 
(Tu) e os Yiba Masa (M), sendo os últimos afins dos Ide Masa e constituindo parte do outro segmento dos Makuna.

Jackson está correta ao afirmar que, na região do Vaupés, a língua funciona como um emblema codificado da identidade do grupo (1983:165). No entanto, é muito mais do que isto. É também uma manifestação da essência, do espírito e da potência do grupo, uma essência e uma potência que estão condensadas nos vários nomes sagrados que um grupo possui e na língua que fala. Isto é evidente nas palavras utilizadas para denotar a própria linguagem. Em Barasana, nyemero, "língua" [o órgão], oka, "queixo", e o sufixo possessivo -ye nas expressões yüa-ye, mü-ye, ou ina-ye, "o que pertence a nós, a você ou a eles", todos se referem à "língua" [linguagem]. De modo mais abstrato, em frases como buti-oka, "força", kuni-oka, "proteção, poder defensivo", ou guari-oka, "impetuosidade, poder agressivo", oka significa "comportamento, qualidade, capacidade, disposição etc." . Do mesmo modo, na maioria ou em todas as línguas da família tukano, wame significa tanto "nome" quanto "coisa", enquanto na língua tukano propriamente dita, wame-ro ("nome-coisa") significa "força". Os nomes são a essência das coisas.

Basere, os "encantamentos soprados", a elocução silenciosamente proferida dos nomes esotéricos dos seres vivos, serve para controlar ou transformar as manifestações do seu espírito. Os nomes próprios e sagrados de indivíduos (basere wame) são atribuídos pelo sopro, um processo que envolve üsü wasoase, a "transformação da alma, do espírito". Do mesmo modo, os encantamentos soprados sobre os alimentos derivados de animais para torná-los seguros envolvem a listagem dos nomes esotéricos de todos os animais na classe relevante, junto com as injunções performativas que lavam, limpam, quebram ou por outros meios neutralizam seus potentes atributos. Assim, as capacidades e essências, as línguas dos diferentes grupos são inerentemente distintas. Não importa muito se são, de fato, idênticas, como na "endogamia lingüística" dos Makuna ou Cubeo; quase idênticas, como no caso dos Barasana e seus afins Taiwano; ou muito diferentes, como entre os Barasana e Tatuio5 ${ }^{5}$. Em essência, elas são sempre diferentes. O mesmo se aplica aos ornamentos plumários e aos instrumentos musicais sagrados. Os ornamentos e instrumentos de todos os grupos tukano parecem idênticos e são feitos dos mesmos materiais, mas seus nomes e origens míticas são específicos ao grupo, os instrumentos são os ossos de seus ancestrais e cada grupo dá voz a eles à sua maneira.

Cada grupo está dividido em um ou mais conjuntos de clãs hierarquizados, cujos ancestrais são os filhos da cobra ancestral original, classificados por sua ordem de nascimento. Cada clã tem um ou mais nomes 
sagrados (basere wame, wame goro). Em certos casos são os mesmos do clã ancestral, em alguns são os nomes dados ao clã por seu ancestral e em outros são derivados do nome do ancestral. Esses nomes sagrados encarnam a potência e a essência do clã e são, normalmente, pronunciados apenas no contexto e nas formas especiais de discurso utilizados durante os encontros rituais; no discurso ordinário, os clãs são referidos por seus nomes comuns ou pelos nomes jocosos (wame, ahari wame).

Enquanto seus filhos, os ancestrais do clã são partes destotalizadas e manifestações da cobra ancestral, assim como os instrumentos sagrados e outras parafernálias rituais são seus ossos e outras partes do corpo. Os processos de destotalização e geração implicam a transição entre dois estados. No plano das origens, os filhos estão mais próximos de se tornarem humanos do que o pai; na vida humana, os pais estão mais próximos aos ancestrais e à ancestralidade do que seus filhos. Os ancestrais da cobra são regularmente referidos como "filhos". Assim, no contexto das narrativas míticas conhecidas de todos, o ancestral dos Bará figura como uma divindade chamada Wai Pino (B) ou "Cobra Peixe", enquanto no contexto dos cantos bará relacionados a suas próprias origens, ele figura como Wai Pino Makü (B), "Filho da Cobra Peixe". As flautas sagradas e os trompetes ou jurupari (LG), os ossos do ancestral, também são seus filhos, em si mesmos pessoas, seres espirituais (hee) transicionais entre os verdadeiros ancestrais e os verdadeiros humanos. Eles não têm carne nem sangue, mas têm almas, vozes e nomes sagrados que se sobrepõem àqueles dos ancestrais do clã e aos nomes de seres humanos verdadeiros.

Além de seu próprio nome sagrado e do(s) nome(s) de seu ancestral, cada grupo tem, assim, nomes para os ancestrais de seus clãs componentes, nomes para os clãs em si, nomes para os instrumentos sagrados e nomes para os seus componentes humanos vivos. Dado que os ancestrais do clã e as flautas são, ambos, partes destotalizadas da mesma entidade, pois as flautas são ancestrais do clã com uma aparência diferente e as pessoas vivas portam os nomes dos mortos, há alguma justaposição, mas não total, entre esses diferentes conjuntos de nomes, tanto em termos de seus nomes reais quanto em termos de referência semântica. A complexa elaboração de nomes para ancestrais, grupos e clãs é um traço marcante da cultura tukano (ver, p. ex., Brüzzi Alves da Silva 1962:69-136; Fulop 1954) e cercada de muito sigilo e de interpretações políticas e rivais. Mais do que tentar especificar a relação precisa entre esses conjuntos de nomes provavelmente uma tarefa impossível — ofereço os seguintes exemplos.

Yeba Meni Hino e Meni Kumu são nomes sagrados do ancestral dos Barasana (LG), um grupo cujas autodenominações incluem Hanera e Yeba 
Masa. Meni figura outra vez em Meni Masa, "Povo Meni", o nome de um clã barasana, e tanto Yeba quanto Meni figuram como os nomes sagrados dos indivíduos masculinos barasana. Do mesmo modo, Maha, "Arara", é, ao mesmo tempo, um nome sagrado para indivíduos do sexo masculino, o nome de uma flauta sagrada e o nome de uma divindade que é, em si, uma manifestação de Yeba Meni Hino, o ancestral do grupo barasana. Mais uma vez, os Bará, descendentes da Cobra Peixe, são o povo da água (ver acima); Lia Kata, "Pato", e Yawira, ambos são nomes de mulheres bará. Os patos vivem na água e Yawira é filha da Cobra Peixe.

Tudo isso é relevante pois, como observa Lévi-Strauss acerca de sistemas de nominação similares, entre indivíduo, clã e grupo exogâmico, "há uma homologia entre o sistema de indivíduos no interior da classe e o sistema de classes no interior de categorias superiores" (1966:172; ver, também, S. Hugh-Jones 1977). No entanto, com os Tukano, não encontramos, de fato, um sistema bem arrumado em que os nomes dos indivíduos são consistentemente "partes" literais dos nomes de clã ou nomes de clã literalmente "partes de" nomes de grupos, como nos casos discutidos por LéviStrauss (1966:173-174) em que, por exemplo, os homens de um clã Urso portam nomes tais como Garra de Urso, Urso Negro, Urso Corredor etc.

\section{Nomes Pessoais}

Vimos acima que as divindades, os ancestrais, os instrumentos sagrados e os seres humanos todos têm (um ou mais) nomes pessoais. Cães e onças, ambos yai, também têm nomes pessoais ${ }^{6}$, enquanto outros animais possuem apenas designações de espécie. Esses nomes de espécie também são usados para se dirigir aos animais de estimação - como, por exemplo, "porco do mato, vem cá!". Os nomes de muitos pássaros e sapos são onomatopéicos - o que significa que revelam seus próprios nomes não apenas na sua coloração distintiva mas também nos seus cantos ou gritos. Além de seus nomes cotidianos, mamíferos, pássaros e peixes têm um ou mais nomes esotéricos que podem ser utilizados em encantamentos para evitar que causem males. Esses nomes são o aspecto espiritual de seus referentes, de modo que nomear algo é conferir poder, uma peculiaridade que se aplica também aos nomes secretos de grupos e indivíduos.

Os indivíduos tukano têm três tipos de nomes pessoais: nomes de espírito, apelidos e nomes de estrangeiro. Cada grupo exogâmico possui um conjunto particular de nomes de espírito específicos quanto ao gênero (basere wame, bükü wame, "nome xamânico ou antigo") ${ }^{7}$. Quando nasce 
uma criança, é dado a ela um nome pertencente a esse repertório e que foi previamente portado por uma pessoa morta do mesmo grupo, da segunda geração ascendente, um pai do pai (FF) real ou classificatório para meninos e uma irmã do pai do pai (FFZ) para meninas. Os indivíduos recebem, portanto, nomes de membros falecidos do grupo, tal como estes haviam recebido os seus nomes; os nomes dos vivos são logicamente os nomes dos ancestrais. Como o conjunto de nomes é restrito, dois ou mais indivíduos terão freqüentemente o mesmo nome.

As pessoas enfatizam que o portador anterior do nome não está reencarnado na criança; esta substitui o epônimo mas não fica no seu lugar. Crucialmente, não há equivalente para as relações de nominação timbira, em que a equivalência mútua entre os homônimos significa que um receptor mais novo tomará a posição social de seu homônimo mais velho e vai se dirigir aos outros pelos termos de parentesco usados pelo epônimo. O nome é comparado a uma fenda ou a um espaço oco (toti) que deve ser mantido preenchido, de modo que todos os nomes disponíveis continuem em circulação. Através da nominação, o indivíduo adquire a identidade de grupo e uma parte da alma do grupo, enquanto a coletividade dos viventes é a continuação dos ancestrais e mantém vivos suas memórias, nomes e vitalidade.

Cada nome é pensado como incorporando qualidades particulares que se ligam ao portador, um ponto vinculado à especialização de papéis. Em teoria, a posição hierárquica do clã é associada à ocupação, de modo que o clã situado no topo, ou os "irmãos mais velhos", são os chefes, seguidos pelos dançarinos e cantadores, guerreiros, xamãs e servos, em ordem descendente. Também em teoria, o mais velho de um grupo de germanos masculino deveria ser o chefe da maloca, o seguinte um dançarino e assim por diante. Os nomes de espírito também estão ligados a essas idéias, de modo que, para as crianças do sexo masculino, o xamanismo e a escolha do nome ao nascer deveriam determinar o papel que assumirá na vida adulta. Na prática, não há nenhuma divisão de trabalho entre clãs diferentes e manter uma rígida correspondência entre papel, ordem de nascimento e nome seria difícil de alcançar de modo sistemático. Não disponho de nenhuma evidência de que isto aconteça, além do fato de as pessoas, às vezes, afirmarem que seu nome é um "nome de dançarino" ou "um nome de guerreiro" (ver, p. ex., Århem 1984:177 e ss., n. 20; 1981:128). Essas afirmações podem estar relacionadas ao uso de honoríficos. Além de bükü/ büküo, "velho", amplamente utilizado para indicar respeito (como em Mario bükü/Sofia büküo), os honoríficos kumu e baya indicam os papéis de xamã e dançarino (como em Pedru kumu or Sira baya). Ao longo do 
tempo, e a partir de um precedente especialmente notável, um marcador de papel social pode acoplar-se a um nome particular; assim, nem todos hoje chamados Sira baya são efetivamente dançarinos.

Os nomes sagrados ou espirituais formam um aspecto do espírito não corpóreo ou alma (üsü), fornecem um elo direto com os ancestrais e são um aspecto íntimo, secreto do eu. As crianças, especialmente as filhas, são freqüentemente chamadas por seus nomes de espírito, tanto em referência quanto no vocativo, mas este hábito cessa quando atingem a puberdade. Os adultos não mencionam seus próprios nomes de espírito, não os revelam aos outros e podem se ofender se os ouvem falados. Estes nomes são raramente usados em referência, de modo que, para além do grupo de parentesco próximo, o nome de espírito de uma pessoa é geralmente conhecido apenas por ouvir falar. Em contextos comuns, apelidos, nomes de estrangeiros ou termos de parentesco são usados tanto em referência como no vocativo.

Além de um ou mais nomes de espírito, as pessoas têm regularmente pelo menos um apelido. Os apelidos (ahari wame, nome "jocoso") correm ao longo de um espectro. Em uma extremidade estão os nomes jocosos verdadeiros, a maioria dos quais se refere ao mundo dos mamíferos, pássaros e peixes: Maka Hino, "Jibóia", Yese Hoa, "Cabelo de Porco do Mato", Siru, "Japim/Xexéu/Rouxinol-do-Rio-Negro" e Wani Hiko, "Rabo de peixe-geográfico" são exemplos. Aqui, as palavras perdem seus referentes originais: aquele que é chamado Jibóia não é de modo algum uma cobra. Outros apelidos têm alguma referência direta ou oblíqua à vida, aos hábitos, à aparência física ou caráter do portador: como uma criança Riti, "Carvão", que estava sempre suja, e Güso Lise, "Boca de Jacaré, que fora mordido uma vez por um jacaré. Inventados e empregados por diversos Outros, esses nomes não transferíveis e biográficos servem para individualizar o portador. Na outra extremidade do espectro estão os nomes comuns, veneráveis, semi-sagrados, cujo conteúdo semântico é semelhante aos dos verdadeiros nomes jocosos dos quais, suspeito, eles podem derivar, mas que agora formam par com nomes de espírito e são transmitidos com eles.

Embora não sejam secretos nem sagrados, os nomes jocosos de um adulto são, no entanto, íntimos e demandam respeito. Freqüentemente usados em referência por aqueles que os conhecem, são empregados como vocativos principalmente por parentes e amigos. Entre os afins de sexo masculino, a zombaria que envolve os apelidos é um componente quase obrigatório da jocosidade ritualizada que ocorre nas festas de cauim. Mais lugar comum ainda são os nomes de estrangeiro (gawa wame), a maioria nomes cristãos colombianos ou brasileiros que são, em geral, abreviados 
e modificados tanto de acordo com as demandas da fonologia das diferentes línguas tukano, quanto com o capricho individual. Embora possam ser alterados ou acrescentados mais tarde, nomes como estes são conferidos logo após o nascimento, quase sempre pelos pais, mas, idealmente, por um agente externo e, melhor ainda, por um missionário em um rito de batismo. Tal como os nomes jocosos, os nomes de estrangeiros podem formar par com os nomes de espírito, de modo que, através de várias gerações, diferentes indivíduos podem compartilhar a mesma combinação de nomes sagrados e nomes de estrangeiros.

Após o nascimento de uma criança, o pai ou a mãe podem ser tecnonimicamente denominados por qualquer um dos nomes da criança, como em Hatira Hako/ü, "mãe/pai de Hatira". A forma "mãe/pai da criança" (suka hako/ü) também é usada. Embora os outros possam se referir a um homem ou a uma mulher como "mãe/pai de X", o uso da tecnonímia como vocativo é quase exclusivamente restrito aos pais entre si, sendo tipicamente o marido quem se dirige à esposa através da referência ao seu filho. Este uso tende a diminuir à medida que a criança cresce, mas se reinicia quando nasce uma nova criança. Portanto, em contraste com os Araweté (ver Viveiros de Castro 1992:143), o caráter temporário e móvel da tecnonímia significa que não se pode dizer que o primogênito seja o que dá nome aos pais. Além do mais, a tecnonímia tukano é sempre transgeracional e assim, diferentemente do padrão araweté (Viveiros de Castro 1992:144), um homem nunca pode ser tratado como "parceiro de X". Finalmente, embora não haja evitação explícita, as pessoas mostram uma certa relutância em nomear ou mesmo em se referir aos que morreram recentemente. Se o fazem, têm o cuidado de apor o sufixo -nymabori, o equivalente ao espanhol "finado", ao nome relevante ou termo de parentesco.

\section{Endonímia e exonímia}

Antes de prosseguir, vale a pena enfatizar alguns dos principais pontos que emergem do material apresentado acima. Deveria estar claro agora que os nomes de espírito tukano estão, de várias maneiras, ligados aos nomes e à constituição dos grupos aos quais pertencem. Os nomes de espírito são os nomes dos ancestrais do clã, são propriedade dos grupos exogâmicos aos quais pertencem os clãs e servem para perpetuar a existência e a vitalidade do grupo que está acima e além da vida dos indivíduos que, temporariamente, são seus portadores. Os nomes são partes de um todo e, ao portar um nome, o indivíduo em questão compartilha a vitalidade do gru- 
po e é identificado com ele. Além disso, assim como os indivíduos têm nomes de três tipos diferentes, os grupos exogâmicos e clãs também são conhecidos por uma combinação de nomes sagrados, apelidos e nomes de estrangeiro.

Viveiros de Castro (1992:155) observa que, assim como os grupos tupi obtêm suas esposas no interior do grupo e seus nomes fora dele, a endonímia dos Tukano e dos Jê também é a contrapartida de uma ênfase na exogamia, um ponto que será mais explorado adiante em relação às noções de alma e espírito.

O tom geral do sistema de nominação tukano é, na verdade, endonímico: os nomes sagrados, os que realmente importam, são transmitidos internamente ao grupo, servem para perpetuar a sua existência e têm função genérica e classificatória, em que a outorga de um nome oriundo de um conjunto determinado estabelece e afirma o pertencimento ao clã e ao grupo. No entanto, os nomes que as pessoas usam em sua vida diária e que servem para individualizá-las vêm de fora. Isto é inteiramente verdadeiro em relação aos nomes de estrangeiros, que são externos por definição.

Em um nível mundano, esses nomes exóticos são uma alternativa conveniente aos nomes indígenas secretos e, junto com os patronímicos colombianos e brasileiros, compreendem partes desejadas e cada vez mais necessárias do processo de modernização. Mais esotericamente, esses nomes também incorporam os poderes exóticos e externos (ewa) dos estrangeiros. O caso mais óbvio em questão foi a adoção do nome Cristo pelos líderes dos movimentos messiânicos do século XIX, e o uso de nomes como Santiago e Poro (Paulo) pelos adeptos do culto. No entanto, para alguns Tukano mais "tradicionais", mas de modo mais difuso, essa apropriação de poderes dos estrangeiros incorporada em seus nomes continua até o presente. Se os nomes sagrados são manifestações de ancestralidade, alma ou espírito, então os nomes de estrangeiros podem ser manifestações de antiespírito e os brancos seriam como antiancestrais. Duas coisas justificam esta sugestão. Por um lado, com a morte, os nomes de espírito retornam às casas de origem ancestrais, ou casas de transformação (masa yuhiri wii, "casas do despertar das pessoas"), situadas nas corredeiras e nas saliências rochosas. Por outro, os xamãs falam dos espíritos dos mortos vivendo em uma morada celestial completa, com geradores, lâmpadas de rua e todos os outros adereços das cidades locais colombianas e brasileiras.

Em contraste com ambos os tipos de nomes espiritualmente carregados, os apelidos mundanos referem-se aos aspectos corporais da pessoa e 
à sua biografia individual ${ }^{8}$. Mas os apelidos também partilham uma certa qualidade externa tanto porque muitos deles (talvez a maioria) aludem direta ou indiretamente ao mundo dos animais, quanto porque surgem como camadas adicionais de vestimentas atribuídas por Outros na vida subseqüente, enquanto os ossos e os nomes sagrados são aspectos integrais e interiores do eu e da alma adquirida no início na vida (ver, também, C. Hugh-Jones 1979:134-135).

Apesar da orientação externa predominante da cosmologia araweté, sua preferência por dar aos primogênitos nomes de membros falecidos do grupo confere uma qualidade endonímica ao seu sistema de nominação. Viveiros de Castro sugere que essa aparente inversão se relaciona ao fato de que, para os Araweté, os nomes pessoais têm, comparativamente, um "baixo rendimento sociológico e cosmológico" e desempenham apenas um papel subordinado, secundário em sua estrutura cosmológica (1992:150151). Para os Tukano, os elementos de exonímia em seu sistema de nominação, predominantemente endonímico, são consistentes com uma complementaridade mais geral entre dois modos de reprodução e continuidade, um linear e baseado na transmissão de sêmen, ossos, nomes e outras manifestações internas de substâncias anímicas no interior do grupo agnático, e outro materno, exterior e associado à afinidade. Os Pano têm um sistema de nominação endonímico que funde os traços jê e tukano, mas ainda depende do exterior para a produção de "identidades" (Viveiros de Castro 1992:155). As identidades tukano provêm largamente do seu interior, no entanto é como se dependessem do exterior para a produção de corpos. Isto fica claro nos eventos que cercam o nascimento e a outorga de nomes de que vamos tratar agora.

\section{Nascimento e Nominação}

O processo de nominação acompanha os processos de desenvolvimento, de modo que uma pessoa adquire nomes no início da vida e deve despirse deles no fim. A maior parte das informações disponíveis sobre os eventos que cercam o nascimento tukano não procede de observação em primeira mão, mas de depoimentos gerais e idealizados, a maioria deles prestada por homens. Apesar dessas limitações, todas as fontes parecem concordar nos pontos principais. O que se segue é um breve resumo baseado nos meus dados e em duas fontes inéditas sobre os Makuna ${ }^{9}$.

Uma mulher, normalmente, dá à luz nas roças de mandioca em torno da casa; ela é, em geral, assistida por sua sogra ou outra mulher experien- 
te que se torna a "madrinha" (masolio) da criança. Não há homens presentes. O bebê é pintado com tinta preta (wee) e banhado no rio; a mãe, então, retorna à casa onde o rosto e o corpo do recém-nascido são ungidos com pintura vermelha (günanya). Antes de sua entrada, os homens removem de dentro dela todos os bens domésticos - itens rituais, armas, bancos, potes e outros aparatos de cozinha etc. - e eles mesmos saem da casa. Um xamã faz então a fumigação desta com cera de abelha incandescente, um ato que marca a separação entre os vivos e o mundo dos espíritos (ver S. Hugh-Jones 1979:186-189). Os pais e a criança ficam então de três a dez dias reclusos juntos, em um compartimento no interior da casa. Durante esse período, as atividades e a dieta de ambos ficam restritas para evitar males à criança; em particular, o pai deve abster-se do trabalho. O fim da reclusão, com seus alimentos e outras restrições, é marcado pelo banho no rio dos pais e da criança, tendo a água sido antes tornada segura através da fumaça (de lenha, tabaco ou cera de abelha) soprada por um xamã, ou um homem ou uma mulher mais velhos. Antes do banho, a mãe e o bebê têm a pele pintada com uma tintura preta (wee), todos os bens domésticos são mais uma vez removidos, os moradores saem e a casa é novamente fumigada com cera incandescente. Uma vez de volta a esta, o bebê é novamente ungido com pintura vermelha. Agora é considerado completamente humano e seus pais podem retomar gradualmente sua dieta e as atividades normais.

Os grupos tukano mais centrais e ao norte, como os Desana, Cubeo e Tukano, adiam a nominação até que os ossos da criança estejam duros e ela comece a andar e falar, considerando que os nomes são muito "pesados" e potentes para serem portados por bebês pequenos. Aqueles que vivem na região do Pirá-Paraná e nas redondezas conferem nomes às suas crianças logo após o nascimento; neste caso, a justificativa é que a nominação "transforma e modifica a alma" (üsü wasoase) da criança, dandolhe força e vitalidade e aumentando suas chances de sobrevivência.

Como a mãe dá à luz na roça, o xamã (kumu), idealmente o parente agnático do pai da criança, submete-se a um processo paralelo, sentandose em um banco durante horas a fio enquanto sopra encantamentos sobre a pintura vermelha e/ou a cera de abelha (basere, wanore). Em seus pensamentos, ele viaja para a casa de origem do grupo ou casa de transformação (masa yuhiri wii), onde ele localiza a criança em forma de espírito. Consultando os ancestrais (hee büküra), ele também escolhe um nome e um papel ritual para a criança e adivinha seu destino e os perigos que lhe podem ocorrer na vida. Ele, então, acompanha e protege a criança-espírito (üsü) e o nome, enquanto juntos eles se movem gradualmente do mun- 
do espiritual imaterial dos ancestrais para assumir forma material aqui e agora, o bebê como carne e sangue, o nome como pintura vermelha (para meninas) ou cera de abelha (para meninos) aplicadas em seu corpo. O nome é o hee üsü ma, "o caminho da alma ou elo com os ancestrais" e enquanto o xamã sopra, o seu sopro confere vida, um processo de transformação que começa durante o trabalho de parto, mas que só é concluído no final do período de reclusão.

A partir deste breve relato, emerge um padrão de nascimento duplo, que é ao mesmo tempo material e espiritual, que acontece tanto na roça como no rio, que vem tanto da mãe quanto do xamã, e que é reduplicado nas seqüências paralelas do banho, que estruturam o período de reclusão. O corpo do bebê é formado por substâncias fornecidas por ambos os pais: o sêmen paterno se torna osso e o sangue materno se converte em carne e sangue. Como uma entidade viva, o bebê também tem um coração, pulmões e respiração — todos eles üsü. A linha de sêmen que passa do pai para a criança e a relativa durabilidade dos ossos em relação à carne são importantes idiomas de patrilinearidade tukano. Os instrumentos sagrados mostrados aos rapazes na iniciação são, simultaneamente, os ancestrais do clã e os ossos do único ancestral do grupo que adota os iniciandos como filhos (ver S. Hugh-Jones 1977). Sob forma simbólica, esses ritos também envolvem a transmissão de sêmen dos mais velhos para os mais novos (ver S. Hugh-Jones 2001).

Se as idéias tukano que dizem respeito à concepção revelam uma relação complementar entre sêmen/osso agnático e carne/sangue por afinidade, os rituais que envolvem o nascimento introduzem um novo ordenamento ao mesmo tema. Inicialmente, marido e esposa estão separados: quando a mãe dá à luz, o pai fica com os outros homens. Esta separação é enfatizada e encerrada pelo banho dado pela mãe em seu filho, pela incandescência da cera de abelha e pela remoção dos homens e dos bens da casa, ações idênticas àquelas que marcam o fim da fase exclusivamente masculina dos ritos de iniciação (ver S. Hugh-Jones 1979:186-189). No entanto, após a separação inicial, o pai, a mãe e o recém-nascido são tratados como uma unidade implicada no bem-estar corporal da criança e complementar ao papel do xamã de localizar seu nome e sua alma. Os pais ficam reclusos juntos e as restrições relacionadas, em particular, às atividades do pai, marcam um elo de substância comum: o que ele faz pode fazer mal ao corpo e à vitalidade da criança. O xamã, como um tipo de "pai" está sujeito às mesmas restrições que os pais verdadeiros.

A vitalidade da criança, üsü, contrapõe-se ao seu nome e espírito üsü aqui como "alma-nome", que está sob os cuidados do xamã e não pro- 
vém do pai, mas da coletividade de ancestrais e, em particular, de um "avô" recentemente falecido. A contribuição de ossos do pai é relativamente durável, o nome do ancestral indiscutivelmente também. Comparando os nomes às flautas sagradas, aos ornamentos plumários e a outros bens, um xamã makuna afirma: "eles são como o sol — não apodrecem" (ver, também, C. Hugh-Jones 1979:134-135). É apenas no final da reclusão, quando o corpo e o espírito da criança, alma-corpo e alma-nome, estão completamente unidos que ela é considerada completamente humana ${ }^{10}$, um momento marcado tanto pelo banho conjunto dos pais com a criança, como pela queima de mais cera de abelha e por uma nova remoção dos bens domésticos.

Uma seção de um mito que forma a base de grande parte do xamanismo envolvendo o parto esclarece esse padrão de duplo nascimento. Sugere também que se a origem material dos bebês está nas mulheres, sua origem espiritual está no rio, assim como todos os Tukano afirmam uma origem aquática única a partir dos ancestrais saídos da Cobra d'Água. Depois que a mãe de Warimi foi morta pelas onças, ele escapa para o rio, sob a forma de espírito. Ali ele brinca com um grupo de crianças que tramam agarrá-lo. Enterram uma menina na margem arenosa do rio, urinam sobre sua pélvis e se afastam. Enquanto Warimi brinca com as borboletas atraídas pela urina, ela bate suas pernas e lhe dá à luz, encarnado em uma criança (ver S. Hugh-Jones 1979:277).

\section{Nomes e ornamentos}

Os Bororo e Kayapó do Brasil Central estabelecem um forte elo entre os nomes e os ornamentos que formam a identidade e a riqueza de seus clãs, segmentos residenciais ou casas. Sempre mantendo o controle e a propriedade definitivos, os membros desses grupos de perfil "matrilinear" circulam essa riqueza entre si como um modo de estabelecer relações interpessoais e construir prestígio. Quando um homem se torna pai na casa de sua esposa, seu nome retorna para o filho de sua irmã na sua casa natal; o nome de uma mulher passa para a filha de seu irmão em uma outra casa, mas deve retornar mais tarde para a fonte (Lea 1992; 1995). Este elo entre os nomes e os ornamentos também é verdadeiro para os Tukano, sendo provavelmente significativo para eles o fato de os pássaros, cujas penas são utilizadas na confecção desses ornamentos, também falarem seus nomes quando gritam. Mas aqui o sistema se transforma. Em lugar de atuarem como sinais diacríticos visíveis de identidade, os ornamentos principais 
dos diferentes grupos tukano são idênticos na forma e diferem apenas no nome e na origem mítica; em vez de grupos "matrilineares", os nomes e os ornamentos são de propriedade dos clãs patrilineares que, ao invés de circularem sua riqueza, guardam-na primordialmente para si mesmos ${ }^{11}$.

Ao nascer, junto com seu nome, uma criança tukano recebe apenas a decoração mínima sob a forma de pintura vermelha e preta. A pintura vermelha, como o "sangue", serve para aumentar a vitalidade da criança: os Cubeo (e talvez outros grupos) dizem que a pintura preta ajuda a criança a soltar sua pele fetal (Goldman 1972:169). Na iniciação — um ritual que representa um segundo nascimento e que repete as seqüências do banho e da pintura descritas acima — , os meninos são considerados fortes o suficiente para começar a usar os poderosos cocares e outros ornamentos que marcam seu status de adultos. Ao mesmo tempo, o xamã-guardião do menino $(g u)$ reafirma o papel que foi escolhido para ele ao nascer. $\mathrm{O}$ iniciando pode também receber um ou mais nomes de espírito adicionais. Esta também é a ocasião em que tais nomes deixam finalmente de ser usados aberta e publicamente. Portanto, o momento em que os nomes de um rapaz - componente pessoal do poder e da identidade do grupo - se tornam completamente internalizados, e deixam de ser pronunciados, é também o momento em que ele começa a exibir aspectos mais gerais de seu poder sob a forma de ornamentos.

Os ornamentos que hoje os homens adultos tukano usam nas danças são provenientes de três fontes distintas. Em primeiro lugar, cada homem veste um conjunto idêntico composto por um cocar, um cinturão de dentes, uma tanga e outros artigos que ele retira de uma caixa especial que é propriedade coletiva de seu clã. Em segundo, os homens usam seus próprios cordões de miçangas e outros acessórios, muitos dos quais adquiridos no comércio local. Finalmente, também usam roupas, toalhas, sapatos e outros artigos que obtêm dos brancos. Os ornamentos de um homem podem, assim, ser vistos como o complemento visual de seus nomes, pois em cada caso eles provêm de três diferentes fontes: de seu clã, de seus amigos e vizinhos e de estrangeiros.

Os distintos aspectos da pessoa que são construídos ao longo de sua vida se separam na morte. A carne apodrece deixando os ossos, mais duráveis, e a alma ou üsü, como a vitalidade, torna-se sombra (wüho) e espectro (wati) que pairam em torno do cadáver para assombrar os vivos. Os homens importantes são enterrados com ornamentos plumários. O rio do mundo subterrâneo é descrito como inundado com os pertences de valor do morto, e os mitos de origem tukano descrevem os mortos chegando na terra como espíritos de ornamentos plumários, que assumem forma hu- 
mana ao viajar rio acima no interior da canoa-cobra ancestral (ver Kumu e Kenhíri 1980:62). Embora ninguém tenha me afirmado isto diretamente, a implicação seria que tanto os nomes quanto os ornamentos circulam entre os vivos e os mortos. Os ornamentos vêm dos ancestrais como bens que são herdados no interior do grupo. Os ornamentos no rio subterrâneo também são manifestações tangíveis dos nomes de clãs que retornam às casas dos ancestrais situadas nos rochedos que formam as corredeiras e nas colinas. Os nomes permanecem nessas casas até o nascimento de uma nova criança. Uma outra implicação seria aquela de que uma pessoa só estará completamente morta quando seus nomes tiverem retornado aos vivos.

\section{Conclusão}

Pode-se concluir, a partir do exposto, que os nomes pessoais tukano constituem parte de um conjunto de idéias que dizem respeito a diferentes aspectos ou componentes do corpo e da pessoa - sangue, ossos, carne e pele: pintura, ornamento e vestimenta; língua, encantamentos, cantos e música; sopro, espírito vital, alma e sombra. Tipos diferentes de nome pessoal também estão ligados a distintas esferas de relações sociais: nomes de espírito para as relações agnáticas ou clânicas; apelidos para as relações com amigos e vizinhos; e nomes estrangeiros para as relações com os brancos. Tais nomes também devem ser vistos no contexto do ciclo de vida onde os processos de conexão e desconexão fazem e desfazem a pessoa. Finalmente, como contrapartida dos ornamentos e dos instrumentos sagrados, os nomes entram em uma complexa interação entre o segredo e a revelação, o encobrimento e a exibição.

Os nomes de espírito ou sagrados pertencem a um conjunto que inclui o sêmen e os ossos paterna ou agnaticamente derivados, além de ornamentos, flautas sagradas, a língua, os cantos e as danças que foram transmitidos internamente ao grupo como propriedade durável ou bens herdados. Estes são complementados por um conjunto mais efêmero que vem de fora: carne e sangue derivados do lado materno, as pinturas que as mulheres fazem e aplicam nos corpos dos homens, os nomes estrangeiros e os cantos que as mulheres compõem para si mesmas. Os apelidos também pertencem, em parte, a este conjunto: alguns vêm dos pais e parentes, mas muitos constituem parte das provocações jocosas características das relações entre afins de sexo masculino.

Como os ossos de uma pessoa, os seus nomes sagrados vêm de dentro do grupo e constituem parte de uma vitalidade e de uma força interior 
encobertas e fortemente guardadas ${ }^{12}$. Seus outros nomes são abertamente revelados de diferentes maneiras e para distintas categorias de Outros como sua identidade pública. Seus nomes de espírito pertencem a um grupo cujos clãs componentes só revelam seus nomes coletivos esotéricos no discurso ritual, em cerimônias coletivas. Durante os rituais de troca cerimonial, os clãs exibem sua força e vitalidade através do canto, dança e ornamentação, cantando histórias de origem que detalham como seus ancestrais adquiriram as prerrogativas que validam sua posição e identidade. Durante os ritos de iniciação, os homens do clã revelam para os jovens iniciandos os ossos do ancestral nos instrumentos musicais sagrados, e ensinam-lhes os nomes e as proezas de seus ancestrais. Tal como a vitalidade, a essência e a identidade, algo dos nomes deve ser revelado. Os homens adultos não revelam seus nomes secretos, mas nos rituais eles agem como pássaros. Do mesmo modo que os pássaros revelam seus nomes em cantos onomatopéicos e na plumagem colorida, os homens vestem seus nomes em seus corpos como ornamentos, tocam-nos nas flautas e entoamnos em seus cantos e músicas.

Tudo isso representa uma permutação particular tukano de um conjunto de idéias amplamente difundido na Amazônia. Os seus paralelos mais próximos são encontrados entre os Bororo e os grupos jê do Brasil Central, todos situados na extremidade endonímica do espectro sugerido por Viveiros de Castro. Embora não demarcadas como duas categorias claramente distintas e nominadas, as idéias tukano que dizem respeito às almas-nome (üsü), aos ornamentos e ancestrais (hee), por um lado, e ao sopro/vitalidade (üsü) e sangue, por outro, estão muito próximas aos princípios bororo de aroe e bope, respectivamente, essência imortal, nome, espírito e ornamento versus processo, sangue, vitalidade e entropia (ver Crocker 1985).

Há, também, paralelos próximos entre o sistema de nominação tukano e o dos kayapó e outros grupos jê do norte. Em ambos os casos, encontramos grupos de tipo "linhagem" - "patrilineares" para os Tukano e "matrilineares" para os Jê — cuja identidade, existência e continuidade dependem do controle e da transmissão de conjuntos de nomes e prerrogativas rituais sobre ornamentos. Vinculada aos ornamentos e aos ritos de nominação, a categoria kayapó de nekrets, ou "riqueza", é muito próxima ao gaheuni barasana, uma categoria que engloba todos os bens e posses, mas que se aplica em particular à riqueza cerimonial, propriedade de cada grupo exogâmico e de seus clãs componentes. A distinção kayapó entre nomes "bonitos" e "comuns", os primeiros usados em cerimônias de nominação coletivas junto com ornamentos elaborados (Turner 1991; 
Verswijver 1992:74 e ss.), cria distinções que são de algum modo análogas à hierarquia dos clãs dos Tukano.

No entanto, há algumas diferenças importantes entre os Tukano e os Jê. A diferença feita pelos Jê entre as relações de nominação e as relações de substância ou filiação encontra algum eco nos eventos que envolvem o nascimento tukano. Estes enfatizam os elos substantivos entre os pais e a criança, tanto em oposição ao papel do xamã como nominador como ao daquele que busca os nomes. Há, na verdade, uma relação especial entre uma criança e o xamã que lhe dá o nome, mas esta relação está baseada não em um nome partilhado, mas no papel mais geral do xamã em proteger a criança após o período do nascimento. O xamã é idealmente um parente agnático do pai da criança, e o ato de nominá-la transforma-o em seu guardião ritual ou co-pai $(g u)$, um elo ritual importante que será (idealmente) replicado e reforçado no rito de iniciação masculina ou de puberdade feminina.

Mais uma vez, os nomes tukano vêm dos avós, assim como os nomes jê vêm de uma categoria que assimila aos avós os germanos (de sexo oposto) dos pais. Mas a diferença crucial reside no fato de que, para os Jê, os nomes são transmitidos entre pessoas vivas, tipicamente, do irmão da mãe e da irmã do pai para os sobrinhos/as. Esta transmissão intervivos dá origem a uma relação cerimonial especial entre nominador e nominando, e também diz respeito ao fato de que aqueles que compartilham nomes são estruturalmente equivalentes. Esta equivalência estrutural significa que, embora as combinações particulares de tais nomes sirvam para individualizar, os nomes são basicamente classificatórios e relacionados a posições sociais fixas através das quais as pessoas circulam no tempo.

No caso tukano, a relação entre o nominado e o epônimo é entre o vivo e o morto, não há relação especial entre indivíduos vivos que compartilham nomes, e embora a afiliação de grupo esteja ligada à nominação, os nomes em si não denotam posições sociais fixas. De acordo com isso, o processo de dar nomes é relativamente menos ritualizado do que entre os Jê, e nunca constitui parte de uma cerimônia pública e coletiva.

Os nomes foram excluídos dos estudos de parentesco clássicos, em parte porque eram considerados infra-sociais, em parte porque o parentesco era visto quase que exclusivamente em termos de procriação. Embora não seja amplamente reconhecido além dos círculos americanistas, o trabalho do projeto Harvard Brasil Central (ver Maybury-Lewis 1979) sobre as relações baseadas nos nomes entre os Bororo e os Jê, efetivamente, desafiou a identificação do parentesco à procriação e prefigurou o que agora se tornou conhecido como o "novo parentesco" (ver Carsten 2000). 
O papel das relações baseadas nos nomes na constituição e perpetuação de grupos sociais no Brasil Central colocou problemas para a aplicação de noções de "descendência"13. Os paralelos entre os Tukano e os Jê sugeririam que, se os Tukano devem ser descritos como "patrilineares", então deve ficar claro que isto deve ser compreendido à luz do material sobre onomástica apresentado aqui (ver, também, S. Hugh-Jones 1995). Este material também reforça a tese de que a procriação em si é uma noção culturalmente específica, incluindo processos de transmissão e outorga de nomes.

Como sugeriu Viveiros de Castro, o sistema de nominação endonímico tukano é, em muitos aspectos, semelhante ao dos Jê e distante daqueles sistemas exonímicos de grupos amazônicos mais típicos, como os Araweté (Viveiros de Castro 1992), Parakanã (Fausto 2001) ou Pirahã (Gonçalves 1993). Nestes casos, os nomes vêm de agentes externos — animais, inimigos, deuses e mortos - e tanto as fontes como a outorga de nomes têm regularmente fortes conotações de afinidade. Além disso, em grupos como os Tupinambá, que estão próximos do pólo exonímico, a ênfase está na aquisição individual de novos nomes que não devem ser depois transmitidos.

No entanto, um dos objetivos deste trabalho foi ampliar e dar polimento aos insights de Viveiros de Castro à luz de dados mais completos sobre os Tukano. Conforme indicado acima, de acordo com um sistema de grupos patrilineares que dependem de seus afins para reprodução, o sistema tukano difere tanto daquele dos Jê como dos Araweté, mas por razões muito diferentes, ao combinar endonímia com elementos de exonímia.

\section{Tradução de Iara Ferraz}

Recebido em 10 de junho de 2002

Aprovado em 20 de julho de 2002

Stephen Hugh-Jones é professor em Antropologia Social na University of Cambridge. É autor de The Palm and the Pleiades (1979) e co-editor de About the House (1995). Sua publicação mais recente é "The Gender of some Amazonian Gifts" (2001). 


\section{Notas}

1 Sobre o Brasil Central ver, entre outros, Crocker (1979); Lave (1979); Lea (1992; 1995); e Melatti (1979). Sobre os Pano, ver Erikson (1996:151-170); Kensinger (1995); e Melatti (1977).

2 Ver Koch-Grünberg (1909/10, I:313) - Tuyuka; McGovern (1927:252) - Taiwano; Stradelli (1928/29:537) - Tukano em geral; Brüzzi Aves da Silva (1962:429) - Tukano em geral; Goldman (1972:140) - Cubeo; Reichel-Dolmatoff (1971:140) Desana; C. Hugh-Jones (1979:123-134) - Barasana; Århem (1981:74-75, 112, 128 129; 1984) - Makuna; Vincent (1985:39-52) - Tukano; Chernela (1993:49-50) Wanano; Cayon (1998:142-152) - Makuna.

3 Palavras não especificadas estão em barasana.

4 Derivado da raiz do verbo meni-: "fazer, confeccionar".

5 Os casos de falantes cubeo que se casam com outros falantes cubeo e falantes makuna que se casam com outros falantes makuna são freqüentemente citados como exceções à regra tukano de exogamia lingüística. Isto deixa escapar o sentido da "regra" e tende a sugerir que os Cubeo e os Makuna são "tribos". Muitos falantes cubeo e makuna se casam com falantes de línguas distintas das suas e os Cubeo e os Makuna não são menos parte de um sistema regional que os demais falantes tukano.

6 Alguns destes nomes, como o nosso "Spot" [Pinta], ou o barasana Ohari (de õha- "cinza") para um cão cinza, são idiossincráticos e derivados de características físicas ou comportamentais. Outros, como Tupari ou Yaima provêm de uma classe especial de nomes verdadeiros (e freqüentemente intraduzíveis) de cão/onça. Alguns dizem que as antas também têm nomes muito especiais, mas desconheço exemplos.

7 Embora não disponha de dados para demonstrá-lo, é provável que os diferentes clãs tenham a propriedade de subconjuntos desses nomes. Ver, também, Journet (1995:53-54) sobre os Curripaco.

8 Agradeço a Viveiros de Castro por me chamar a atenção para a relação complementar entre nomes de espírito e nomes de estrangeiros.

9 Cayon (1998) e uma transcrição de uma gravação feita por Roberto Garcia (Makuna) do rio Toaca para o prof. Århem. Sou-lhe grato por ter permitido utilizar esse material.

10 Embora ninguém tenha me afirmado isto, pode-se pensar que este seja o momento no qual a pessoa de quem provém o nome da criança esteja agora completamente morta e se torne um ancestral. 
11 Ornamentos plumários e outras riquezas rituais são ocasionalmente trocados entre grupos de afins para criar uma relação de hee tenyua, "afinidade ancestral". Ver S. Hugh-Jones (1992; 2001).

12 Historicamente, há registros dos Cubeo, Tukano, Tariana e de outros grupos do Vaupés bebendo chicha misturada às cinzas dos ossos incinerados de seus mortos. Ver Wallace (1889:346-347); Coudreau (1886/87, II:173); Koch-Grünberg (1909/ 10, II:152); e Goldman (1972:249-250). Esta forma de "endocanibalismo" seria consistente com as noções relacionadas à reciclagem dos nomes e outras substâncias anímicas no interior do grupo.

${ }^{13}$ Ver Lea (1995) para uma discussão sobre essa questão. 


\section{Referências bibliográficas}

ÅRHEM, K. 1981. Makuna Social Organization. Estocolmo: Almqvist \& Wiksell.

.1984. "Vida y Muerte en la Amazonia Colombiana: Un Relato Etnográfico Makuna". Anthropos, 79: 171-189.

BRÜZZI ALVES DA SILVA, A. 1962. A Civilização Indígena do Uaupés. São Paulo: Linográfica Ed.

CARSTEN, J. (ed.). 2000. Cultures of Relatedness. Cambridge: Cambridge University Press.

CAYON, L. 1998. Asi mismo Hacían los Antiguos, sus Abuelos, los Pensadores Buenos. Dissertação de Mestrado, Universidade de los Andes, Bogotá.

CHERNELA, J. 1993. The Wanano Indians of the Brazilian Amazon. Austin: Texas University Press.

COUDREAU, H. 1886/87. La France Equinoxiale. Paris: Challamel Ainé (2 vols.).

CROCKER, C. 1979. "Selves and Alters among the Eastern Bororo". In: D. Maybury-Lewis (ed.), Dialectical Societies. Cambridge, Mass.: Harvard University Press. pp. 249-300.

_ 1985. Vital Souls. Tucson: University of Arizona Press.

ERIKSON, P. 1996. La Griffe des Ä̈eux. Paris: Peeters.

FAUSTO, C. 2001. Inimigos Fiéis. São Paulo: Editora da Universidade de São Paulo.

FULOP, M. 1954. "Aspectos de la Cultura Tukana: Cosmogonía". Revista Colombiana de Antropología, 3:97137.

GOLDMAN, I. 1972. The Cubeo (2a ed.). Urbana: University of Illinois Press. GONÇALVES, M. 1993. O Significado do
Nome. Rio de Janeiro: Sette Letras.

HUGH-JONES, C. 1979. From the Milk River. Cambridge: Cambridge University Press.

HUGH-JONES, S. 1977. "Like the Leaves on the Forest Floor: Ritual and Social Structure amongst the Barasana". Proceedings of the Forty-Second International Congress of Americanists. Paris.

.1979. The Palm and the Pleiades. Cambridge: Cambridge University Press.

.1992. "Yesterday's Luxuries, Tomorrow's Necessities: Business and Barter in Northwest Amazonia". In: C. Humphrey e S. Hugh-Jones (eds.), Barter, Exchange and Value. Cambridge: Cambridge University Press. pp. 42-74.

.1995. "Insight-out and Back-tofront: The Androgynous House in Northwest Amazonia". In: J. Carsten e S. Hugh-Jones (eds.), About the House. Cambridge: Cambridge University Press. pp. 226-252.

. 2001. "The Gender of some Amazonian Gifts: An Experiment with an Experiment". In: T. Gregor e D. Tuzin (eds.), Gender in Amazonia and Melanesia. Berkeley: University of California Press. pp. 245-278.

JACKSON, J. 1983. The Fish People. Cambridge: Cambridge University Press.

JOURNET, N. 1995. La Paix des Jardins. Paris: Institut d'Ethnologie.

KENSINGER, K. 1995. "Panoan Kinship Terminology and Social Organization". In: How Real People Ought to Live. Prospect Heights, Illinois: Waverland Press. pp. 157-174.

KOCH-GRÜNBERG，T. 1909/10. Zwei 
Jahre unter den Indianern. Berlim:

E.Wasmuth.

KUMU, Umúsin P. e KENHÍRI, Tolamãn. 1980. Antes o Mundo Não Existia. São Paulo: Livraria Cultura Ed.

LAVE, J. 1979. "Cycles and Trends in Krikati Naming Practices". In: D. Maybury-Lewis (ed.), Dialectical Societies. Cambridge, Mass.: Harvard University Press. pp. 16-44.

LEA, V. 1992. “Mebengokre (Kayapó) Onomastics: A Facet of Houses as Total Social Facts in Central Brazil". Man, 27:129-153.

.1995. "The Houses of the Mebengokre (Kayapó) of Central Brazil: A New Door to their Social Organisation". In: J. Carsten e S. Hugh-Jones (eds.), About the House. Cambridge: Cambridge University Press. pp. 206-225.

LÉVI-STRAUSS, C. 1966. The Savage Mind. London: Weidenfeld and Nicolson.

MAYBURY-LEWIS, D. (ed.). 1979. Dialectical Societies. Cambridge, Mass.: Harvard University Press.

MCGOVERN, W. 1927. Jungle Paths and Inca Ruins. London: Hutchinson.

MELATTI, J. C. 1977. “Estrutura Social Marubo: Um Sistema Australiano na Amazônia". Anuário Antropológico, 76:83-120.

. 1979. "The Relationship System of the Krahó". In: D. Maybury-Lewis (ed.), Dialectical Societies. Cambridge, Mass.: Harvard University Press. pp. 46-79.

REICHEL-DOLMATOFF, G. 1971. Amazonian Cosmos. Chicago: Chicago University Press.

STRADELLI, E. 1928/29. “Vocabulários de Língua Geral, Portuguez-Nhêen- gatú e Nhêengatú-Portuguez". Revista do Instituto Histórico e Geográfico Brasileiro, 158(2):5-768.

TURNER, T. 1991. The Mebengokre Kayapo: History, Social Consciousness and Social Change. Manuscrito inédito.

VERSWIJVER, G. 1992. The Club-Fighters of the Amazon. Gent, Rijksuniversiteit et Gent.

VINCENT, W. 1985. Daxsea Mahsa: Cosmology and Material Culture among the Tukano Indians of Brazil. Ph.D. Dissertation, University of Chicago.

VIVEIROS DE CASTRO, E. 1986. Araweté: Os Deuses Canibais. Rio de Janeiro: Jorge Zahar Ed./ANPOCS. .1992. From the Enemy's Point of View. Chicago: Chicago University Press.

WALLACE, A. R. 1889. Travels on the Amazon and Rio Negro. London: Ward Lock. 


\section{Resumo}

A importância dos sistemas de nominação para a compreensão das sociedades e culturas ameríndias é hoje amplamente reconhecida, mas as informações sobre esse tópico concernentes aos povos Tukano do Noroeste Amazônico permanecem esparsas e dispersas. Tomando os Barasana e seus vizinhos como referência, este artigo apresenta alguns dados básicos quanto à onomástica tukano e discute similaridades entre as patrilinhagens tukano e os grupos de perfil "matrilinear" entre os Jê e os Bororo. Em ambos os casos, nomes e ornamentos estão ligados enquanto aspectos da riqueza e do espírito dos grupos. Por meio de um exame da transmissão onomástica como um dos componentes dos rituais que envolvem o nascimento, o artigo explora também a relação entre nomes, sangue, ossos e sopro como aspectos da pessoa. Finalmente, situa a onomástica tukano em um contexto comparativo mais amplo, argumentando que sua combinação de exonímia e endonímia, assim como a ausência de transmissão intervivos, a distingue das formas mais "puras" de endonímia encontradas entre os Bororo e os Kayapó. Palavras-chave Tukano, Barasana, Nomes, Nascimento, Ornamentos

\section{Abstract}

The importance of systems of naming for an understanding of Amerindian society and culture is now widely recognized but information on this topic relating to the Tukanoan-speaking peoples of north-west Amazonia remains sparse and scattered. Using the Barasana and their neighbours as a point of reference, this article presents some basic data on Tukanoan onomastics and discusses points of similarity between Tukanoan patrilineages and the matrilineage-like groupings amongst the Gê and Bororo. In each case, names and ornaments are linked as aspects of corporate wealth, property and spirit. Through an examination of name transmission as one component of the rituals surrounding childbirth, the article also explores the relation between names, blood, bone and breath as aspects of personhood. Finally it sets Tukanoan onomastics in a wider comparative context, arguing that their combination of exonymy and endonymy and absence of inter-vivos name transmission sets the Tukanoans apart from the more 'pure' form of endonymy found amongst the Bororo and Kayapo.

Key words Tukanoan, Barasana, Names, Birth, Ornaments 